\title{
Extrafacial Loose Areolar (XFLA) Thread Lifting (A Novel Technique)
}

\author{
Ahmed Abdelmoez Alsayed \\ Independent Researcher, Al-Hokail, Khobar, Saudi Arabia \\ Email: az971986@gmail.com
}

How to cite this paper: Alsayed, A.A. (2020) Extrafacial Loose Areolar (XFLA) Thread Lifting (A Novel Technique). Modern Plastic Surgery, 10, 108-119. https://doi.org/10.4236/mps.2020.104013

Received: September 13, 2020

Accepted: October 19, 2020

Published: October 22, 2020

Copyright $\odot 2020$ by author(s) and Scientific Research Publishing Inc. This work is licensed under the Creative Commons Attribution International License (CC BY 4.0).

http://creativecommons.org/licenses/by/4.0/

\begin{abstract}
Thread lifting is one of the widely chosen procedures for minimally invasive facial rejuvenation. Traditional facial thread lifting has nearly inevitable side effects e.g. facial edema, facial bruising, prolonged recovery, skin puckering, and visible and/or palpable threads, as well as less common complications e.g. damage of facial vital structures. Applying the extrafacial loose areolar (XFLA) thread lifting technique by using loose areolar connective tissue, the fourth layer of the scalp, as insertion medium for the threads to be anchored to the layer above (epicranial aponeurosis or galea aponeurotica) and the layer below (pericranium), could help minimize most of the previously mentioned side effects. In this manuscript, technique steps will be detailed to prove its novelty.
\end{abstract}

\section{Keywords}

Extrafacial, Loose, Areolar, Thread, Lift, Scalp

\section{Introduction}

Thread lifts, like all non-invasive procedures, are widely spread. No official statistics are there to estimate their precise popularity. However, the American Society of Plastic Surgeons in its 2019 annual report showed that 1,811,754 aesthetic surgical procedures were done in 2019 versus 18,160,785 of minimally invasive aesthetic procedures done in the same year. Despite developments and innovations in aesthetic surgical sciences, over the past 20 years all facial aesthetic surgical procedures numbers declined dramatically, while other minimally invasive facial aesthetic procedures have shown remarkable growth over the same period of time. The thing indicates the growing trend towards minimally invasive facial aesthetic procedures [1].

Efficacy of thread lift as a procedure has been and is still controversial. On one 
hand, thread lifts are thought to be an effective minimally invasive procedure that can be employed solely or combined with other procedures for temporary facial rejuvenation purposes with less complications and shorter recovery periods [2] [3] [4].

On the other hand, thread lifting is seen as a nearly useless procedure, depending more on the fake plumping effect induced by the immediate post-procedural swelling with poor short termed results and serious complications, especially that it is done under incompletely aseptic measures by practitioners who received few hours of training according to authors who adopt that opinion [5] [6] [7] [8].

A third party, occupying the middle zone of opinions between both extremities, states that thread lifting is fairly effective as a minimally invasive procedure, amplitude and duration wise, and should not be presented as an alternative to surgical facelift. The procedure has variable results according to the practitioner, technique, technology and the case, with a promising future that will follow the innovation regarding technology and techniques [9] [10] [11] [12].

Threads come in different materials and designs:

1) Material: Polypropylene, Polydioxanone, Poly L-lactic acid and Policaprolacton are examples.

2) Design: Soft, with cut or molded barbs/cogs in one or two directions, with cones or spiraled.

3) Attachment: with cannula, one needle or two needles.

4) Coatings: Some brands come coated with Hyaluronic acid or Calcium Hydroxyapatite [2] [5] [8] [9].

Like any procedure, thread lifting has complications:

1) Edema, bruising, prolonged recovery, pain, discomfort and ecchymosis.

2) Skin puckering, pinching or irregularities, visible threads and palpable threads.

3) Inadequate cosmetic result, recurrent laxity, facial asymmetry and patient dissatisfaction.

4) Thread migration, thread exposure and thread disruption.

5) Infection, hair sinuses, inclusion cysts, allergic reaction, granuloma, chronic foreign body sensation and pseudolymphoma.

6) Injury of facial vital structures e.g. nerves, vessels or parotid duct (Stensen duct), hematoma, paresthesia and scarring at entry or exit points [2] [3] [4] [5] [12] [13].

\section{Innovation}

Applying the extrafacial loose areolar (XFLA) thread lifting technique by using loose areolar connective tissue, the fourth layer of the scalp, as the anchorage medium for the threads could help minimize most of the side effects as well as augment results. The technique can be detailed as follows:

1) Disinfect and drape the patient's face. Make sure the technique is sterile. 
2) Mark entry points as shown in Figure 1. Number of points varies according to severity of skin laxity and amount of correction required. Avoid dangerous entry points detailed in relevant anatomy section. Point 8 is about $1 \mathrm{~cm}$ inferior and anterior to the angle of the mandible.

3) Numb each point with $0.5 \mathrm{cc}$ lidocaine using a fine needle (I prefer $33 \mathrm{G}$ needle).

4) Using lidocaine, keep injecting blebs in one line to create a track for the threaded cannula at the last point behind the jawline (blue dots (T) in Figure 1).

5) Start puncturing, only the skin, using $18 \mathrm{G}$ needle. (Tip: pinch the skin while you puncture it if possible, it will decrease the possibility of injuring a blood vessel, free the skin from your pinch and leave the needle inside for a moment, if you are inside a blood vessel you will find blood backflow through the needle).

6) Mold the cannula to be slightly curved, to fit on the skull curves, using its own plastic cap (try not use your hand) (Figure 2). Make sure that the opening on the side of the cannula tip is on the convex part of the curve not to scratch pericranium in case a blunt L-shaped ended cannula is used (Figure 3).

7) Stick the cannula vertically first against the skin till full penetration is felt, then redirect the cannula in the vector direction (Figure 4) to go through loose areolar connective tissue layer of the scalp. Feeling zero resistance and minimizing the pain and discomfort to the least are the signs of being in the right plane (Figure 5). Avoid going through dangerous tracks detailed in the relevant anatomy section. I prefer menton as a reference point for facial vectors that extend from menton to each entry point (Figure 4). Typically, I use one thread per port, except that I use two threads for entry point 8 by the jawline. Make sure you slightly change the vector if you insert more than one thread at the same entry point to keep the anchorage tunnel tight.

8) After inserting all the threads and extracting the cannulas, tract their free
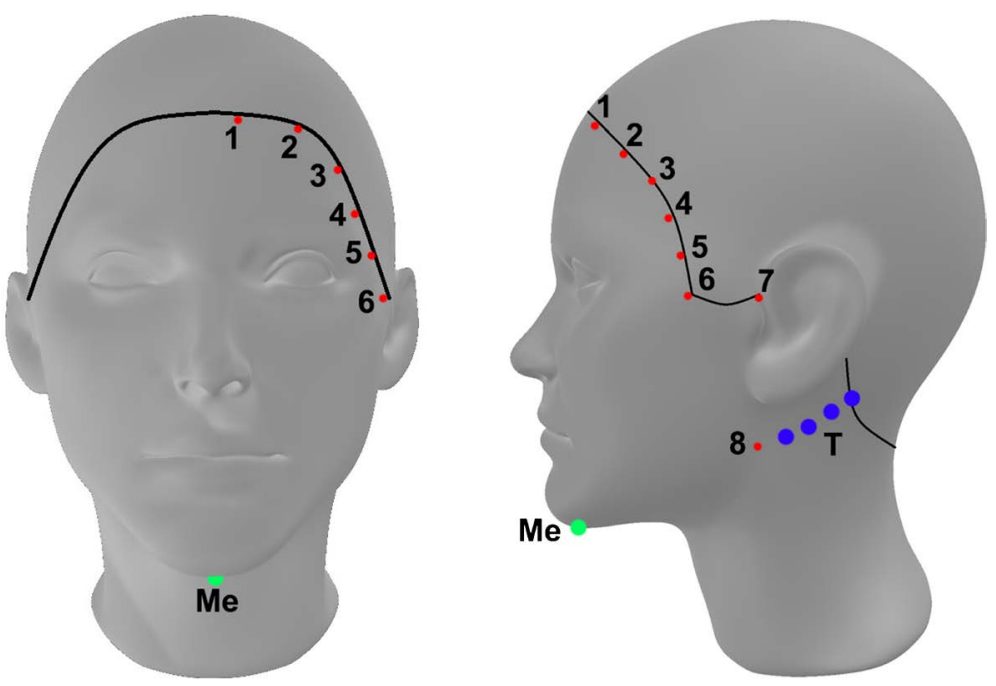

Figure 1. Frontal and lateral views showing entry (red) points (1 - 8), Menton (Me) (green) and track points (blue) next to entry point (8). 


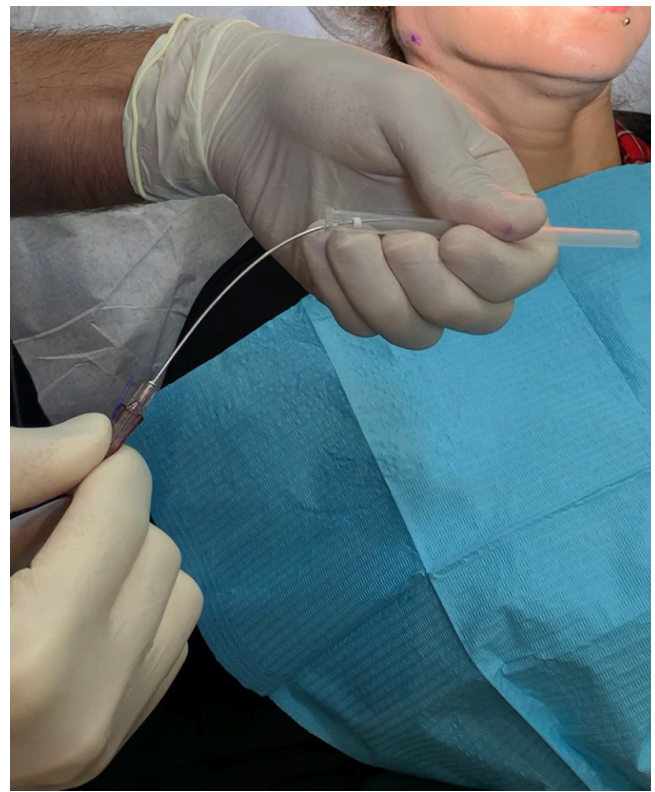

Figure 2. Molding the cannula to be slightly curved, to fit on the skull curves, using its own plastic cap.

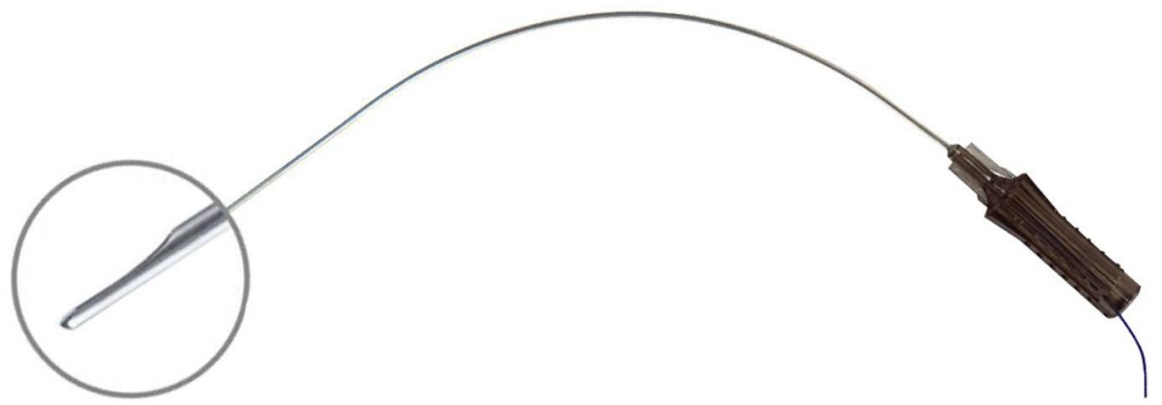

Figure 3. Cannula opening is on the convex part of the curve not to scratch pericranium in case a blunt L-shaped ended cannula is used.
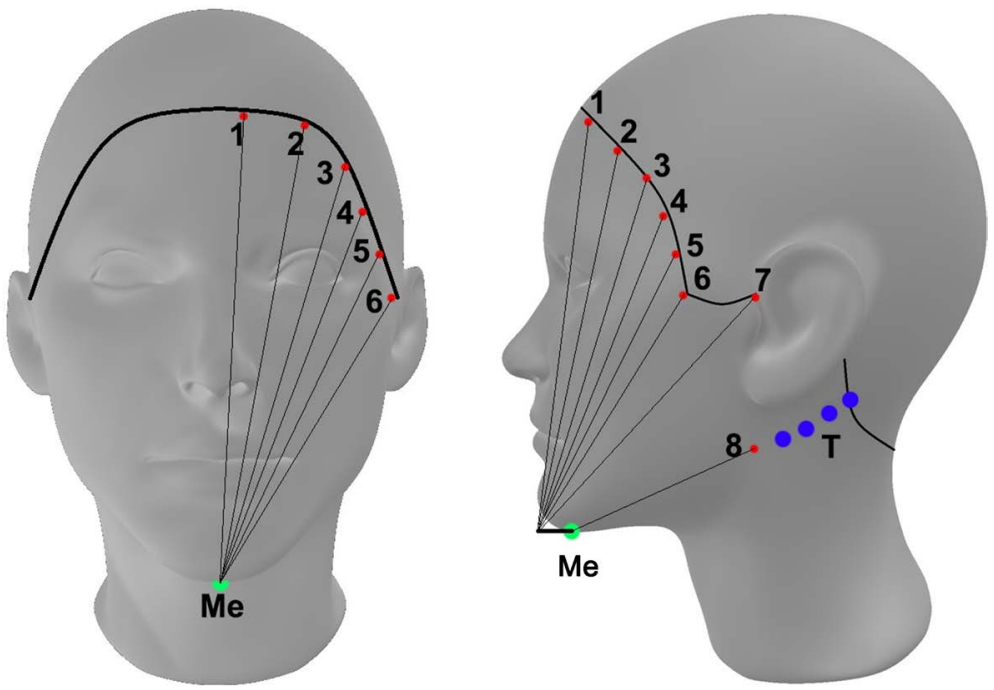

Figure 4. Menton (Me) as a reference point for facial vectors extending from menton (and its horizontal projection) to each entry point. 


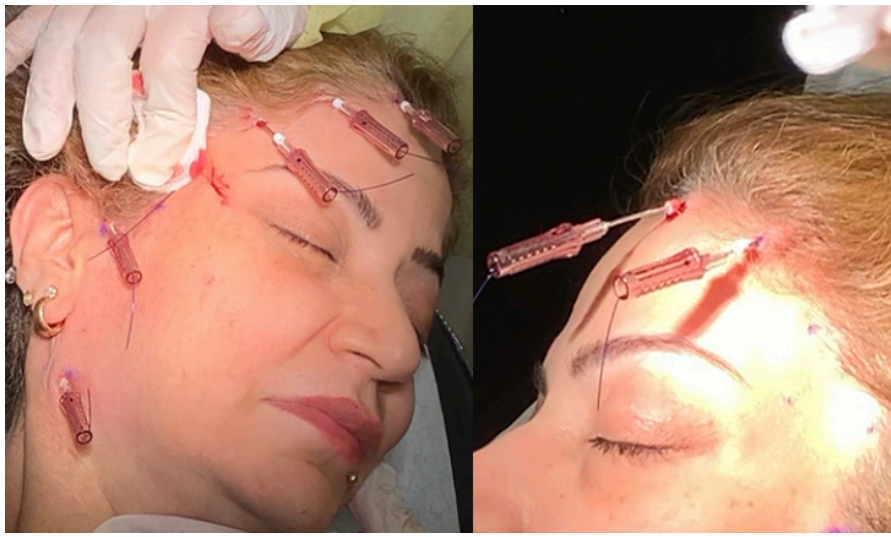

Figure 5. Direction of threaded cannulas insertion during the procedure.

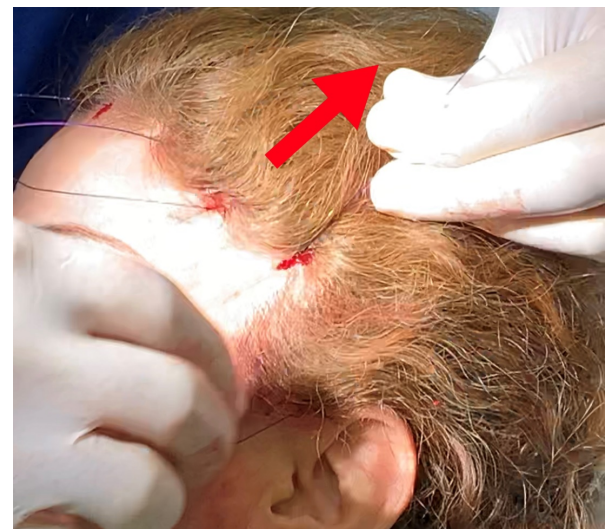

Figure 6. Threads free ends tracted towards the scalp in the vector direction (red arrow).
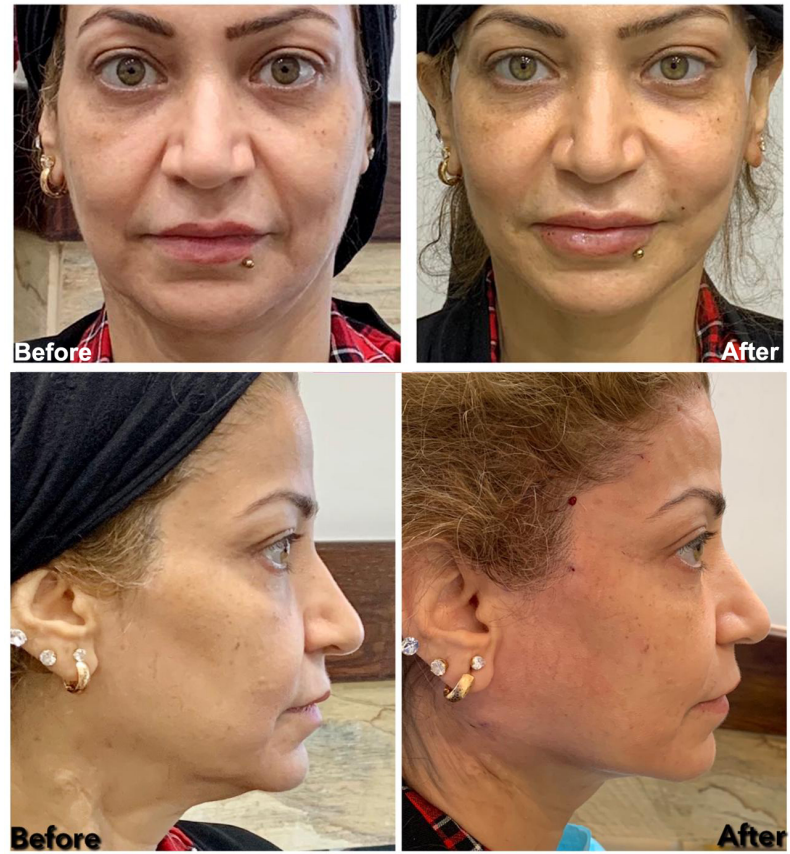

Figure 7. Immediate post-procedural results. In this case particularly, Xline ${ }^{\mathrm{TN}}$ threads were used (Technical specifications: 360 D Barbed COG, cannula L-blunt, 19 G 100 mm, Thread: PDO $180 \mathrm{~mm}$ ). 
ends towards the scalp in the vector direction (Figure 4, Figure 6). Immediate homogenous lifting should be noticed (Figure 7).

9) Disinfect entry points and cover them by adhesive wound closure strips.

10) Prescribe post-procedural medications e.g. antibiotic, analgesic, antiedematous and any other preferred medications.

\section{Relevant Anatomy}

Danger zones related to the described procedure can be classified into:

A) Entry points (Figure 8, Figure 9)

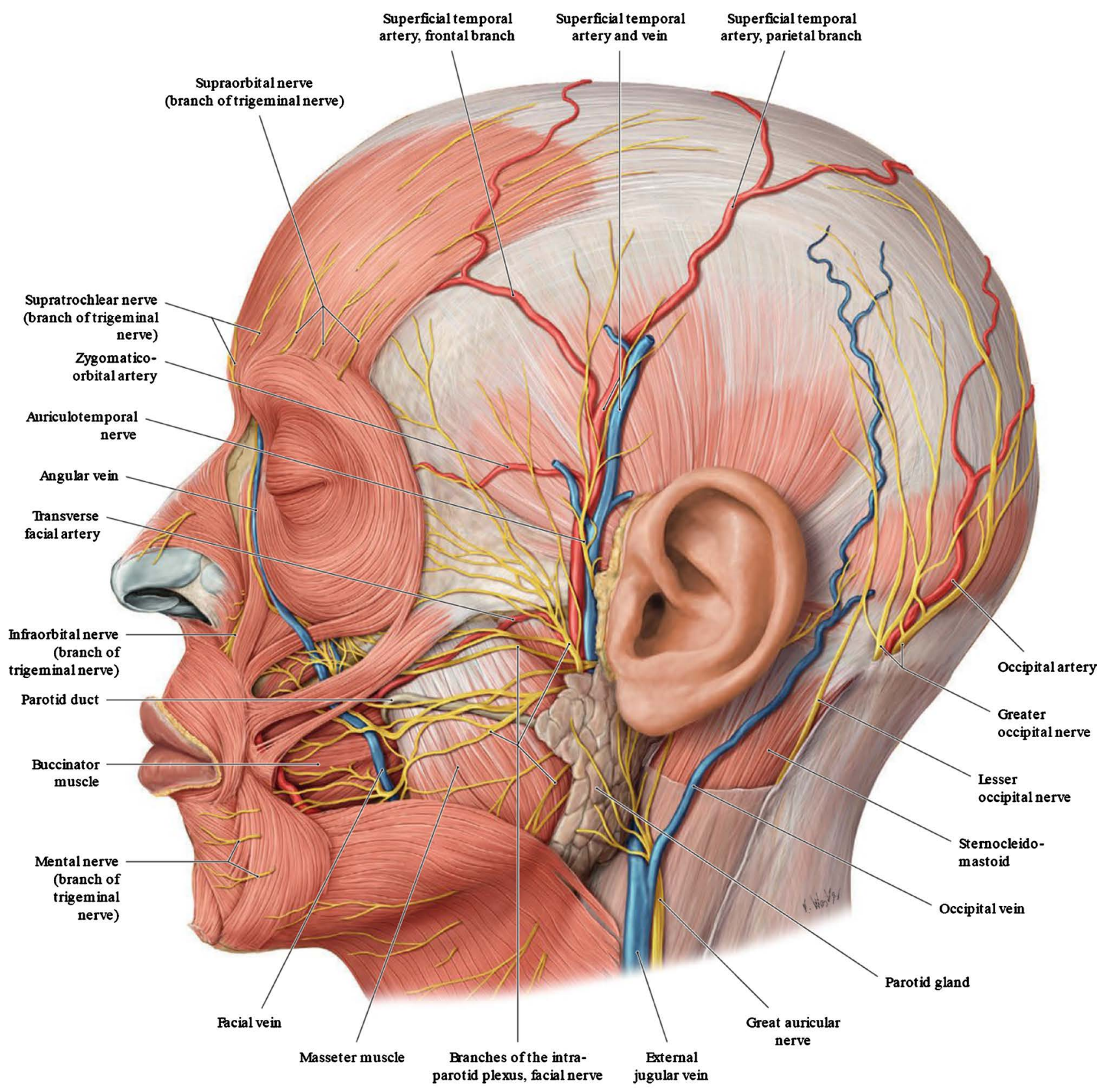

Figure 8. Superficial nerves of the face [16]. 


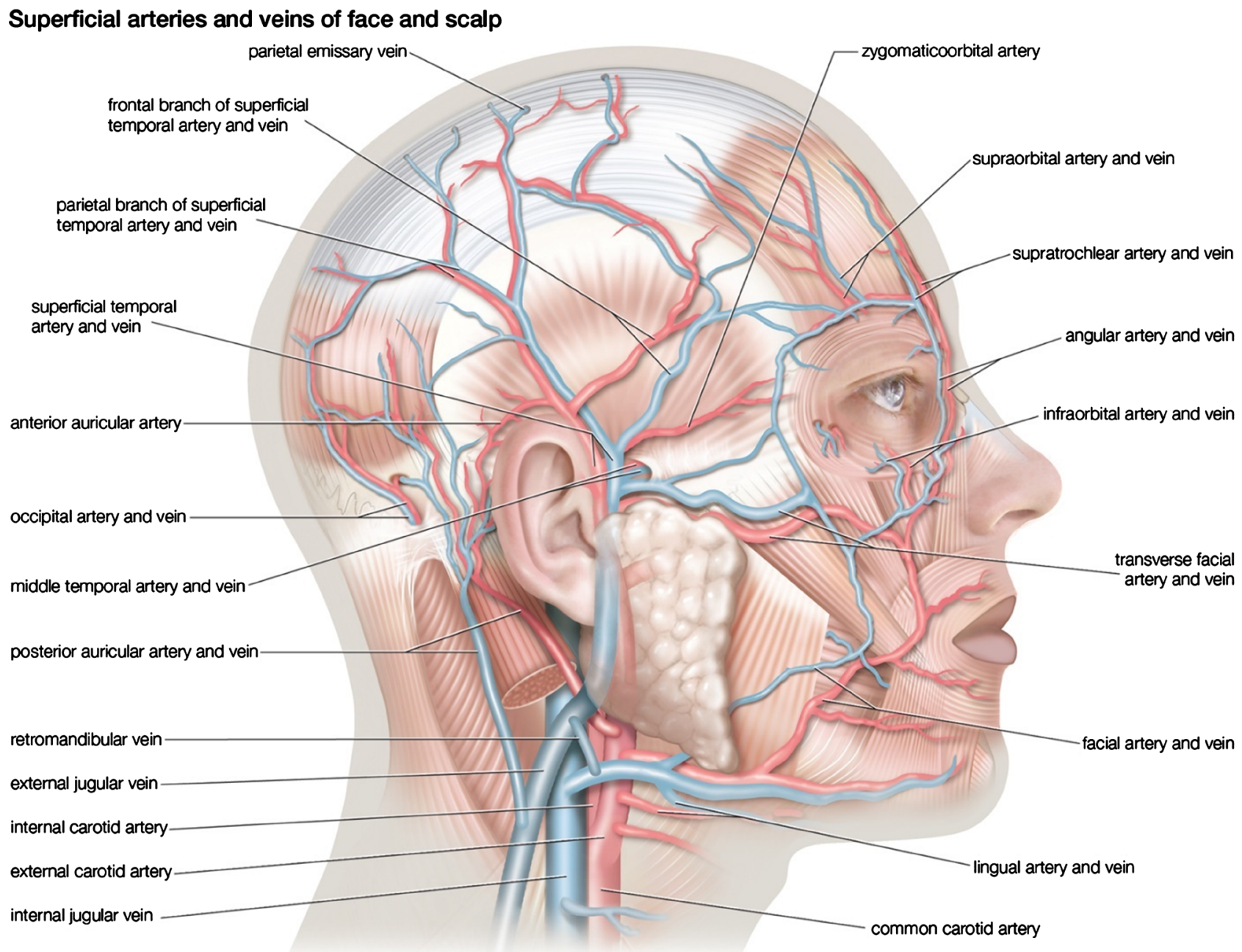

(c) 2010 Encyclopædia Britannica, Inc.

Figure 9. Superficial vessels of the face [17].
1) Supratrochlear vessels
2) Supratrochlear nerve
3) Supraorbital vessels
4) Supraorbital nerve
5) Frontal branch of superficial temporal vessels
6) Zygomaticotemporal vessels
7) Middle temporal vessels
8) Transverse facial vessels
9) Superficial temporal vessels (5, 6, 7, 8 are branches and tributaries)
10) Auriculotemporal nerve
11) External jugular vein
12) Great auricular nerve
The procedure can be safer by:

- Starting local anesthesia infiltration intradermally to augment the field safety level.

- Puncturing the skin only without going deeper. 
- Pinching the skin while puncturing.

- Checking if there is blood backflow from the needle.

- Using blunt cannula.

- Avoiding points with visible, palpable or detectable pulse through a handheld doppler.

- Being aware that there is no fixed surface anatomy for the above structures that can be pinpointed by a ruler. Several studies show that surface anatomy of such structures is variable [14] [15].

\section{B) Insertion and anchorage tracks}

There are five layers to the scalp: the skin, connective tissue layer, galea aponeurotica, loose areolar connective tissue, and the pericranium [18].

In the extrafacial loose areolar (XFLA) thread lifting technique, loose areolar connective tissue, the fourth layer of the scalp, is used as the insertion medium for the threads to be anchored to the layer above (epicranial aponeurosis or galea aponeurotica) and the layer below (pericranium) (Figure 10).

The loose areolar tissue layer has no vital structures running through it, except that certain emissary veins traverse it to connect the scalp veins to the diploic

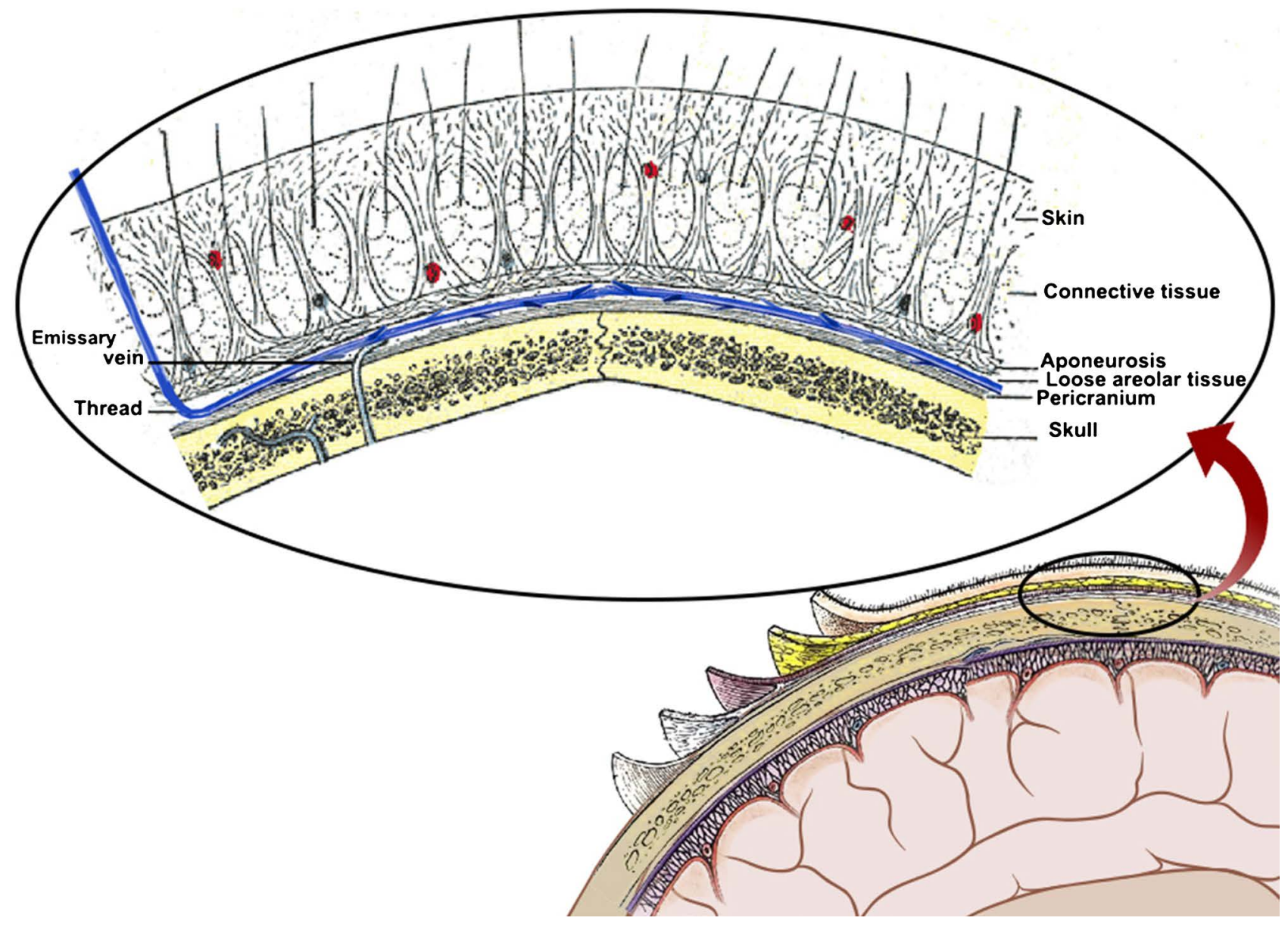

Figure 10. In the extrafacial loose areolar (XFLA) thread lifting technique, loose areolar connective tissue, the fourth layer of the scalp, is used as the insertion medium for the threads to be anchored to the layer above (epicranial aponeurosis or galea aponeurotica) and the layer below (pericranium). 
veins and intracranial venous sinuses. Some of those emissary veins are of significant size and pass through anatomically well-defined foramina on the skull e.g. parietal and mastoid emissary veins (Figure 10). The risk of injuring them during the procedure as described is not significant. However, two precautions have to be taken:

1) Make sure the technique is sterile and prescribe a prophylactic antibiotic after the procedure. The loose areolar connective tissue is a harbor for a potential infection that can spread to the meninges. Named 'the danger zone' of the scalp, the tissue contains valveless emissary veins that have direct access to the cranial cavity. Pus and blood can build up in the flexible tissue, and provide a route for meningitis [19].

2) Keep your patient under supervision for at least 15 minutes after the procedure. Tearing of the emissary veins in the loose areolar connective tissue layer causes the build-up of blood that gets trapped between the tense tissue of the galea aponeurotica and the pericranium. This condition is called a subgaleal hematoma [20].

\section{Conclusion}

Classic facial thread lifting is done by inserting threads into the face. It has nearly inevitable side effects such as facial edema, facial bruising, prolonged recovery, skin puckering, and visible and/or palpable threads, as well as less common complications e.g. damage of facial vital structures (Figure 11).

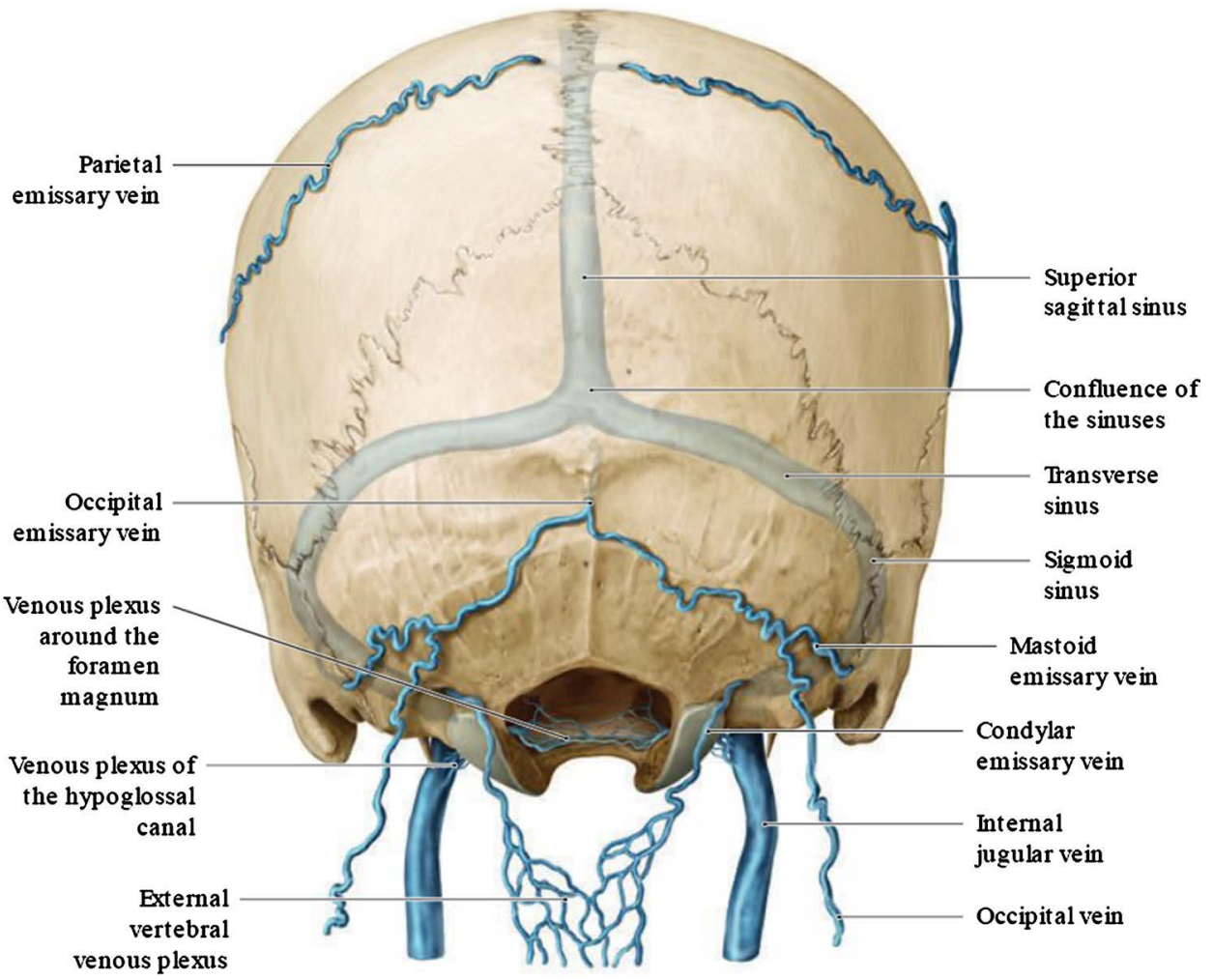

Figure 11. Occipital view showing emissary veins [21]. 


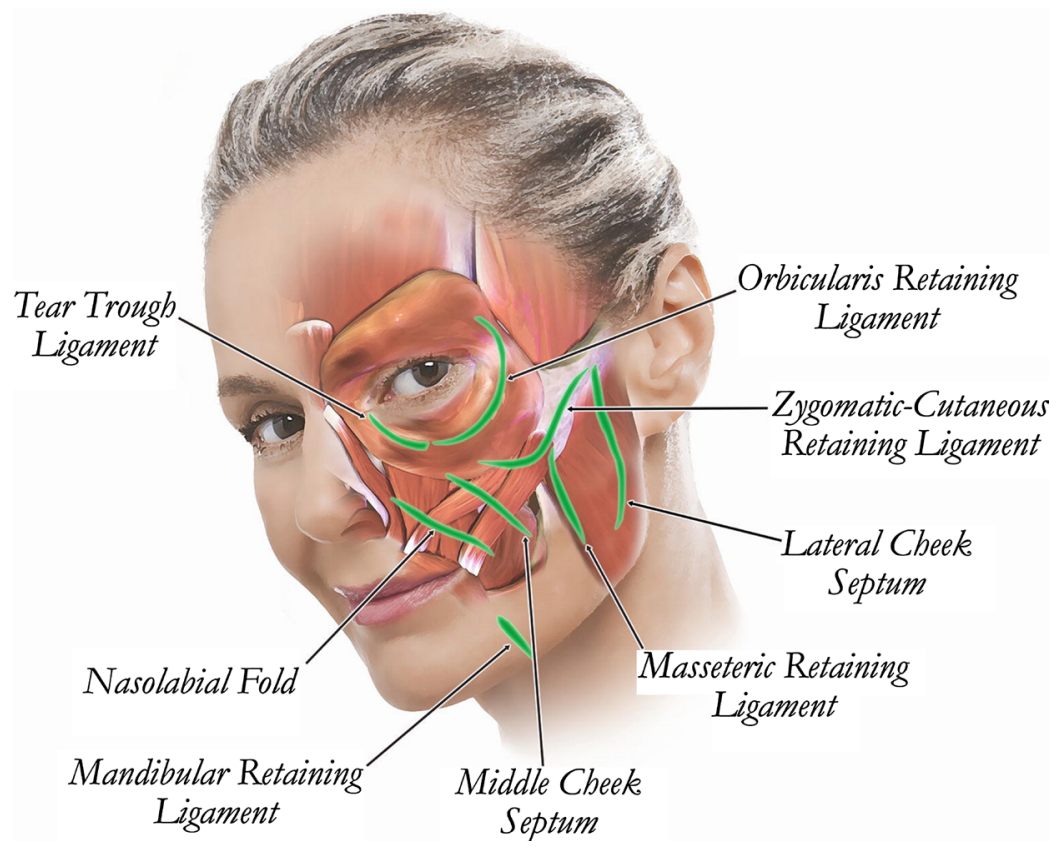

Figure 12. Facial retaining ligaments [22].

Facial layers have a sophisticated structure, variable thicknesses even for the same layer in different spots and variable landscape. This makes it easy to unnoticeably change the plane of cannula insertion.

Most of the cannula tracks made by classic thread lifting will be interrupted in most cases by facial retaining ligaments (Figure 12). This will, in my opinion, hinder homogenous lifting effect and encourage puckering and dimpling.

As mentioned before there is a chance of injuring vital facial structures using the classic facial thread lifting technique e.g. facial vessels, nerves and parotid duct (Stensen duct).

Using the extrafacial loose areolar (XFLA) thread lifting technique solves the above-mentioned challenges with significantly positive results. However, the following prospects and suggestions need to be taken into consideration:

1) Results longevity needs to be estimated.

2) Thread design needs to be modified:

- Cannula: to be longer, already curved and completely blunt rather than L-shaped ended cannula.

- Thread: to be longer (with more cogs in the direction on the outer end side to enhance anchorage) and thicker ( 2 or 3 instead of $2 / 0$ or $1 / 0$ as the loose areolar tissue layer is $1-3 \mathrm{~mm}$ [23], and cogs need to be in contact with the layer above (epicranial aponeurosis or galea aponeurotica) and the layer below (pericranium) to enhance anchorage.

\section{Conflicts of Interest}

The author declares no conflicts of interest regarding the publication of this paper. 


\section{References}

[1] 2019 Plastic Surgery Statistics Report. ASPS National Clearinghouse of Plastic Surgery Procedural Statistics.

https://www.plasticsurgery.org/documents/News/Statistics/2019/plastic-surgery-stat istics-full-report-2019.pdf

[2] Tavares, J., Oliveira, C., Torres, R. and Bahmad, F. (2017) Facial Thread Lifting with Suture Suspension. Brazilian Journal of Otorhinolaryngology, 83, 712-719.

https://doi.org/10.1016/j.bjorl.2017.03.015

[3] Gülbitti, H., Colebunders, B., Pirayesh, A., Bertossi, D. and van der Lei, B. (2018) Thread-Lift Sutures. Plastic and Reconstructive Surgery, 141, 341e-347e. https://doi.org/10.1097/PRS.0000000000004101

[4] Abraham, R.F., DeFatta, R.J. and Williams, E.F. (2009) Thread-Lift for Facial Rejuvenation. Archives of Facial Plastic Surgery, 11, 178-183. https://doi.org/10.1001/archfacial.2009.10

[5] Halepas, S., Chen, X. and Ferneini, E. (2020) Thread-Lift Sutures: Anatomy, Technique, and Review of Current Literature. Journal of Oral and Maxillofacial Surgery, 78, 813-820. https://doi.org/10.1016/j.joms.2019.11.011

[6] Tong, L. and Rieder, E. (2019) Thread-Lifts: A Double-Edged Suture? A Comprehensive Review of the Literature. Dermatologic Surgery, 45, 931-940. https://doi.org/10.1097/DSS.0000000000001921

[7] Fukaya, M. (2017) Long-Term Effect of the Insoluble Thread-Lifting Technique. Clinical, Cosmetic and Investigational Dermatology, 10, 483-491. https://doi.org/10.2147/CCID.S150738

[8] Garvey, P., Ricciardelli, E. and Gampper, T. (2009) Outcomes in Threadlift for Facial Rejuvenation. Annals of Plastic Surgery, 62, 482-485.

https://doi.org/10.1097/SAP.0b013e31818c18ed

[9] Yongtrakul, P., Sirithanabadeekul, P. and Siriphan, P. (2016) Thread Lift: Classification, Technique, and How to Approach to the Patient. International Journal of Medical and Health Sciences, 10, 558-566.

https://publications.waset.org/10005867/thread-lift-classification-technique-and-ho w-to-approach-to-the-patient

[10] Ahmad, M. (2019) Thread Facelift: Satisfaction Rate among the Patients Using FACE-Q. Clinical Practice, 16, No. 3. https://doi.org/10.37532/fmcp.2019.16(3).1139-1143

[11] Rezaee Khiabanloo, S., Jebreili, R., Aalipour, E., Saljoughi, N. and Shahidi, A. (2018) Outcomes in Thread Lift for Face and Neck: A Study Performed with Silhouette Soft and Promo Happy Lift Double Needle, Innovative and Classic Techniques. Journal of Cosmetic Dermatology, 18, 84-93. https://doi.org/10.1111/jocd.12745

[12] Kalra, R. (2008) Use of Barbed Threads in Facial Rejuvenation. Indian Journal of Plastic Surgery, 41, 93-100.

[13] Singh, T., Makhecha, M., Yadav, T. and Atawane, M. (2019) Cutaneous Pseudolymphoma Secondary to Facial Thread Lift Procedure. Indian Dermatology Online Journal, 10, 322-324. https://doi.org/10.4103/idoj.IDOJ_166_18

[14] Gil, Y., Shin, K., Lee, S., Song, W., Koh, K. and Shin, H. (2016) Topography of the Supraorbital Nerve with Reference to the Lacrimal Caruncle: Danger Zone for Direct Browplasty. British Journal of Ophthalmology, 101, 940-945. https://doi.org/10.1136/bjophthalmol-2016-309332

[15] Yano, T., Okazaki, M., Yamaguchi, K. and Akita, K. (2014) Anatomy of the Middle 
Temporal Vein. Plastic and Reconstructive Surgery, 134, 92e-101e. https://doi.org/10.1097/PRS.0000000000000283

[16] Schünke, M., Schulte, E., Schumacher, U., Cass, W., Schünke, M., Schünke, M., et al. (2016) Thieme Atlas of Anatomy. 2nd Edition, Thieme, New York, Stuttgart, Delhi, Rio de Janeiro, 6(4): 222.

[17] Superficial Arteries and Veins of the Face and Scalp. Anatomy. Definition, History, \& Biology [Internet]. Encyclopedia Britannica. https://www.britannica.com/science/anatomy

[18] Tajran, J. and Gosman, A.A. (2020) Anatomy, Head and Neck, Scalp. StatPearls [Internet]. StatPearls Publishing, Treasure Island (FL). https://www.ncbi.nlm.nih.gov/books/NBK551565/

[19] Germann, A.M. and Al Khalili, Y. (2019) Anatomy, Head and Neck, Scalp Veins. StatPearls [Internet]. StatPearls Publishing, Treasure Island (FL).

[20] Chen, C.E., Liao, Z.Z., Lee, Y.H., Liu, C.C., Tang, C.K. and Chen, Y.R. (2017) Subgaleal Hematoma at the Contralateral Side of Scalp Trauma in an Adult. The Journal of Emergency Medicine, 53, e85-e88. https://doi.org/10.1016/j.jemermed.2017.06.007

[21] Schünke, M., Schulte, E., Schumacher, U., Cass, W., Schünke, M., Schünke, M., et al. (2016) Thieme Atlas of Anatomy. 2nd Edition, Thieme, New York, Stuttgart, Delhi, Rio de Janeiro, 4(7): 101.

[22] Cohen, A. and Burkat, C. (2019) Oculofacial, Orbital, and Lacrimal Surgery. Springer, Cham, 32. Anatomy of Facelifting, p.318. https://doi.org/10.1007/978-3-030-14092-2

[23] Tremolada, C., Candiani, P., Signorini, M., Vigano, M. and Donati, L. (1994) The Surgical Anatomy of the Subcutaneous Fascial System of the Scalp. Annals of Plastic Surgery, 32, 8-14. https://doi.org/10.1097/00000637-199401000-00002 